\title{
THE CORRELATION BETWEEN PRICE AND OUTPUT CHANGES WHEN THERE ARE MANY GOODS
}

\author{
Alan V. DEARDORFF* \\ University of Michigan, Ann Arbor, MI 48109, USA
}

Received September 1979

It is shown that competition in the production of many goods implies a positive correlation between the elements of a vector of changes in normalized prices and the corresponding vector of changes in outputs.

A well-known result of general equilibrium theory is that, once many goods are produced, the 'cross elasticities' of supply are theoretically ambiguous. That is to say, a rise in the relative price of one good may cause the output of any other good to rise or fall. It follows that if all prices change at once, no definite statement can be made in general about even the direction of output change for any particular good, and it is tempting to conclude that no statement of any kind can be made about the output response to price changes. The purpose of this note is to show, however, that a simple relationship between prices and outputs does exist for a competituve economy: the correlation between price changes and output changes must be positive. Thus, while the output of any particular good may rise or fall when many prices change, it is nonetheless true that on average price changes are associated with output changes in the same direction.

This result, which I will prove in a moment, is valid for competitively organized production in any context, but it is of particular interest for international trade. In recent years, trade theorists have worked increasingly to extend the standard theorems of international trade beyond the two-good models in which they have most often been formulated and exposited. These efforts have sometimes been frustrated by the sorts of ambiguity and indeterminacy to which general equilibrium models are prone. How, for example, can one predict the pattern of trade when one does not even know the direciion of change of domestic supply? The result of this paper suggests. however, that some progress can be rade toward generalizing our understanding of the international economy if we look for relationships to

*My thanks to Lars Svensson and Hal Varian for disecting me to relevant hiterature, and to Jagdish Bhagwati for his comments and encouragement. 
hold on average across the many vectors of the econorny, rather than for each sector indivicually. ${ }^{1}$

The resilt is also useful in that it can provide a theoretical basis for using regrescion atalysis in empirical work on trade and production. Bhagwati and Srinivasan (1979) survey, for example, a number of studies which seek an empirical relationship between the pattern of protection and the pattern of industrialization. Given the effects of tariffs on prices, our result suggests the legitimacy of regressing output changes on tariff changes, so long as both variables are properly specified.

Consider, then, an economy capable of producing $n$ goods, with vectors of outputs, $X$, constrained to lie within a set of production possibilities. Let $P^{0}$ $=\left(P_{1}^{0}, \ldots, P_{n}^{0}\right)$ and $P^{1}=\left(P_{1}^{1}, \ldots, P_{n}^{1}\right)$ be two different vectors of prices in this economy and $X^{0}=\left(X_{1}^{0}, \ldots, X_{n}^{0}\right)$ and $X^{1}=\left(X_{1}^{1}, \ldots, X_{n}^{1}\right)$ be corresponding vectors oi outputs. Suppose, too, that the prices are normalized to sum to unity, $\sum_{i=1}^{n} P_{1}^{j}=1$ for $j=0,1$. Finally, let $\Delta P=P^{1}-P^{0}$ and $\Delta X=X^{1}-X^{0}$ be the vectors of price and output changes. We show that the elements of these two vectors must be positively' correlated.

To see this, note first that the sign of a correlation is the same as the sign of lite corresponding covariance, which may in turn be written as

$$
\operatorname{cov}(\Delta P, \Delta X)=\Delta P . \Delta X-n \overline{\Delta P} \overline{\Delta X}
$$

where $\overline{\Delta P}$ and $\overline{\Delta X}$ are the means of the vectors $\Delta P$ and $\Delta X$. But the normalization of prices assures that

$$
\overline{\Delta P}=(1 / n) \sum_{i=1}^{n}\left(P_{1}^{1}-P_{i}^{0}\right)=0
$$

so that the covariance of the vectors is in turn simply equal to their inner product. And this may be seen to be positive, as follows.

If outputs are chosen, as by a competitive economy, to maximize the value of national product at prevailing prices, then it must be true that $P^{0} X^{0}$ $>P^{0} X^{1}$ and $P^{1} X^{1}>P^{1} X^{0}{ }^{2}$ Thus, $P^{1} \Delta X>0>P^{0} \Delta X$, which implies $\Delta P \Delta X$ $>0$. . $^{3}$ This completes the demonstration.

\footnotetext{
'In Deardorff (1980) I have taken this approach to generalize the law of comparative advantage.

${ }^{2}$ Strict inequality is not assured by maximization alone when the nax nun is not unique, as in the more-goods-than-factors case analyzed by Samuelson (1953), and Melv 1,1 (1968). However, equality in both of these relationships would imply that both output vectors could have been produced at both sets of prices. With price and output changes both nonzero, thi; would be a pathological case which căn reasonably be ignored.

${ }^{3}$ This is a well-known implication of profit maximization. It was noted for the firm by Samuelson (1947, p. 77) and for the aggregate of all firms by Debreu $(1959$, p. 47). Both authors stated the (more general) weak inequality. The contribution here is to note the sinple link that allow: one to infer a correlation from this inner product.
} 
Note that this result is quite general in terms of the production structure that it assumes. Any number of goods and factors is permitted, as well as any specification of production functions, so long as they give rise to a welldefined set of production possibilities. Joint products are permitted, as is the use of some or all of the goods as intermediate products. In the latter case one can either interpret $X$ as net outputs and $P$ as prices of final goods, or $X$ as gross outputs and $P$ as net (or valued-added) prices. In either case a competitive economy will perform the maximization from which the resuli follows.

The assumption that prices are normalized to sum to unity may appear too strong, but other normalizations would do as well and this was chosen merely for convenience. Some such normalization is needed, however, in order to confine attention to relative prices.

\section{References}

Bhagwati, J.N. and T.N. Srinivasan, 1979, Trade policy and development, in: R. Dornbusch and J. Frenkel, eds., International economic policy (Johns Hopkins, Elaltimorc) 1-35.

Deardorff, A., 1980, The general validity of the law of comparative advantage. Journal of Political Economy, forthcoming.

Debreu, G., 1959, Theory of value (Wiley, New York).

Melvin, J., 1968, Production and trade with two factors and three gonds, American Economic Review 58, 1249-1268.

Samuelson, P.A., 1947, Foundations of economic analysis (Harvard. Cambridge).

Samuelson, P.A., 1953, Prices of factors and goods in general equilibrium, Review of Economic Studies 21. 